\title{
Roll waves and their generation criteria
}

\section{Roll waves e seus critérios de geração}

\author{
Fabiana de Oliveira Ferreira ${ }^{1}$ (D), Geraldo de Freitas Maciel $^{1}$ (D) \& João Batista Pereira ${ }^{1}$ (i) \\ ${ }^{1}$ Universidade Estadual Paulista, Ilha Solteira, SP, Brasil \\ E-mails: fabiana.of@gmail.com (FOF), geraldo.f.maciel@unesp.br (GFM), joao.pereira@unesp.br (JBP)
}

Received: December 09, 2020 - Revised: February 1, 2021 - Accepted: March 7, 2021

\begin{abstract}
Pulsating waves (also known as roll waves) might occur on the free surface of extreme events like mud and debris flows, among others, usually intensifying the caused damage. This technical note aims to inform about the roll wave phenomenon developing in a free-surface laminar flow, and analyze its generation criteria, centered on the concepts of Froude number and disturbance frequency. The complete linear stability analysis of the new depth-averaged model was proven a useful theoretical tool in determining new generation criteria for roll waves developing in non-Newtonian fluids. The results showed that the roll wave generation depends on two criteria: the first is associated to the minimum Froude number, and the second is related to the cut-off frequency. In addition, we have confirmed that the new generation criteria can be verified via numerical simulation based on a second model with full equations (Fluent software). Globally, the emergence of roll waves is favored by the non-Newtonian properties of the flowing fluid and the fact that the cut-off frequency decreases along with the minimum Froude number. Lastly, both generation criteria were tested in order to examine a case study involving the occurrence of roll waves in a watershed.
\end{abstract}

Keywords: Roll waves; Non-Newtonian fluid; Laminar flow; Minimum Froude number; Cut-off frequency.

\section{RESUMO}

Ondas pulsantes (tipo roll waves) podem surgir na superfície livre de eventos extremos como corridas de detritos e lamas, dentre outros, potencializando os danos causados. Esta nota técnica tem por objetivo informar sobre a fenomenologia das roll waves evoluindo na superfície livre de escoamentos laminares e analisar seus critérios de geração com foco nos conceitos de Froude mínimo e da frequência de perturbação. A análise de estabilidade linear completa do novo modelo das equações promediadas na vertical, mostrou-se como ferramenta teórica útil na determinação dos novos critérios de geração de roll waves evoluindo em fluidos não-newtonianos. Os resultados demonstraram que a geração de roll waves depende, de fato, de dois critérios: o primeiro associado ao número de Fronde mínimo e o segundo relacionado à frequência de corte. Além disso, testou-se e confirmou-se que esses novos critérios de geração foram também atendidos, quando da simulação numérica obtida por um segundo modelo baseado nas equações completas, neste caso, o software Fluent. Globalmente, o surgimento de roll waves é favorecido pelas propriedades não-newtonianas do fluido escoante com a frequência de corte diminuindo com o número de Froude. Por fim, ambos os critérios de geração foram aplicados em um estudo de caso com presença de roll waves em uma bacia de drenagem.

Palavras-chave: Roll waves; Fluido não-Newtoniano; Regime laminar; Número de Froude mínimo; Frequência de corte. 


\section{INTRODUCTION}

Roll waves are waves that propagate with constant amplitude, length and velocity, modeled as a wave train, under the action of weight and viscous forces, wall resistances, and surface tensions. They can be also characterized as waves with the aspect of mobile hydraulic jumps (pulsating regime), which are present in the nature. Roll waves can occur in diverse flow situations and contexts: in pressure flows, in free-surface flows or in the interface of multiphased media, in Newtonian or non-Newtonian fluids, under laminar or turbulent regimes, naturally developed (natural roll waves) or under an imposed frequency, as illustrated by Figure 1.

The phenomenon might occur in dam spillways, in natural flows (geophysical) (Bazargan \& Aghebatie, 2015; Arai et al., 2013), in highway traffic (vehicles are treated as fluid particles) (Kuehne, 1984), in gas pipelines (Aydin et. al., 2015) and even in the circulation of human arteries (Brook \& Pedley, 2002). Given the variety of contexts in which they might occur, roll waves can be classified as a multidisciplinary, large spectrum phenomenon, of environmental, social, industrial and medical interest.

There is a propitious domain for the phenomenon to occur in the ambit of "natural" disasters (landslides, mudflows, avalanches, volcanic lavas, superficial flows), depending on topographic, physical (viscosity, for instance) and dynamic factors (like the discharge). Consequently, it also depends on the flow Froude $\left(F r>F r_{\text {min }}\right)$ and Reynolds numbers (Coussot, 1994; Ng \& Mei, 1994; Balmforth \& Liu, 2004; Maciel et al., 2013) and, at the same level, on the involved disturbance frequencies, being all parameters intimately related to the flowing fluid rheology.

It should be noticed that just some of the disturbances neighboring the uniform regime will actually evolve into roll wave state, implying the existence of a frequency band $\left(f_{\min }, f_{\max }\right)$, which assures the phenomenon for a given discharge range. Should it not occur, the disturbances would dampen (Ferreira et al., 2014). Gray \& Edwards (2014) also reported the existance of a cut-off frequency necessary for the generation of disturbances in granular flows. Such finding is in accordance with the experimental results of Forterre \& Pouliquen (2003). Additionally, a minimal channel length $\left(L_{\min }\right)$ is necessary for the propagation of stabilized roll waves (Di Cristo et al., 2013a). Both generation criteria $\left(F r>F r_{\text {min }}\right.$, and $f<f_{\text {critical }(\text { cut }- \text { off })) \text { depend on the rheological properties of the }}$ fluid. Along these lines, such rheological parameters should be accurately quantified, a difficult task, may it be in natural events or under controlled laboratory conditions, especially when taking into account the lack of infrastructure of Brazilian universities for treating the rheology (rheometry) of complex fluids.

Roll wave studies count from the decades of 1910 and 1920 (Cornish, 1910; Jeffreys, 1925) and, since then, they are of high interest to the scientific community. In the decade of 1940 , the classical work of Dressler (1949) opened up a new line of research, calling the attention of the mathematical society. In the end of the 1960's, Brock (1969) proposed his doctoral thesis, analyzing the phenomenon on water, generating and measuring waves in two long channels. When it comes to non-Newtonian fluids, the works of Kajiuchi \& Saito (1984), Ng \& Mei (1994), Liu and Mei (1994) are considered pioneers.

Through time, chiefly in the last 15 years, the roll wave phenomenon has been reported in the physics literature (Liu \& Mei, 1994; Liu \& Gollub, 1994; Needham \& Merkin, 1987; Hwang \& Chang, 1987; Gao et al., 2003), in chemistry (Holmås, 2010), in engineering (He et al., 2020; Mcardell, 2016) and in applied mathematics (Razis et al., 2019; Campomaggiore et al., 2016), under three self-complementary branches: mathematical, numerical and experimental modelling. This reaffirms the multiinter-transdisciplinary aspect of the subject, reflecting in the opportunity/possibility to gather around different researchers

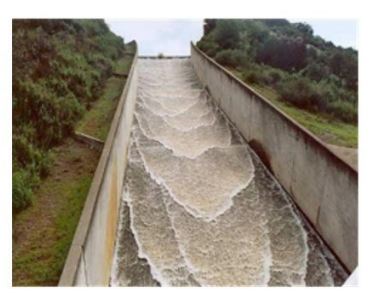

(a)

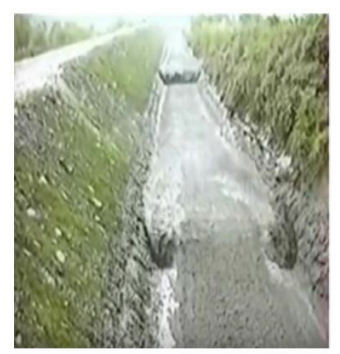

(d)

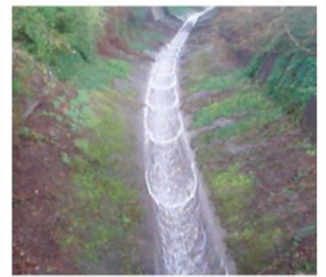

(b)

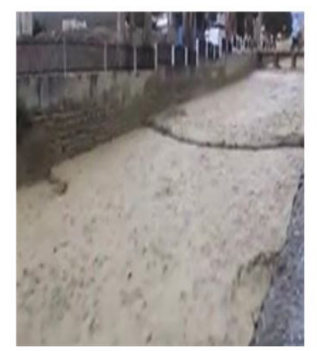

(e)

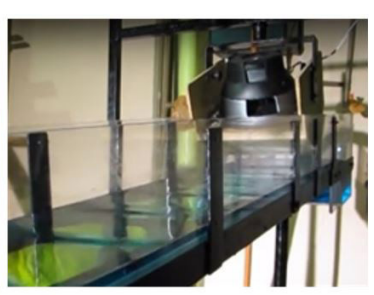

(c)

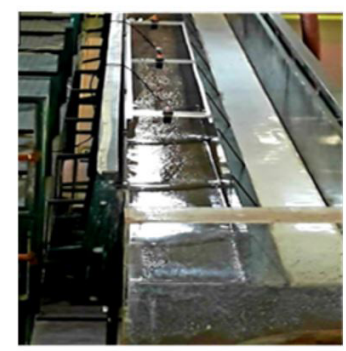

(f)

Figure 1. Roll wave phenomenon in open channels and in experimental tests carried out in laboratories. Roll waves in water: (a) Turner Dam and Reservoir, Vally Center (Ponce, 2005), (b) concrete channel, Lions Bay (Balmforth, 2011), (e) Channelized Achumani River, La Paz (Ponce \& Guzmán, 2019). Roll waves in glycerin: (c) experimental apparatus for roll wave measurements, LH² Lab., Ilha Solteira, Brazil (own authorship). Roll waves in mud: (d) concrete channel (Institut National de Recherche en Sciences et Technologies pour L'environnement et L'agriculture, 2001), (f) experiment in an inclined channel, LH² Lab., Ilha Solteira, Brazil (own authorship). 
and aptitudes. As previously stated, in the event of roll wave generation, may it be in dam spillways or in "natural" disasters, the phenomenon usually intensify the caused damage, not only developing erosive actions and promoting sediment transport, but also generating waves of higher amplitudes, especially in the case of non-Newtonian fluids (Maciel et al., 2018).

Although in reduced numbers, roll wave studies concerning both laminar and turbulent regimes have been experimentally carried out (Brock, 1969; Tamburrino \& Ihle, 2013; Fiorot et al., 2015; Maciel et al., 2017; Zhao et al., 2015; Aranda et al., 2016; Miao et al., 2020; Fei et al., 2021). Works based on mathematical and numerical modelling, on the other hand, are more frequent in the literature (Zanuttigh \& Lamberti, 2002; Gao et al., 2003; Balmforth \& Liu, 2004; Di Cristo \& Vacca, 2005; Maciel et al., 2013; Ferreira et al., 2014; Cao et al., 2015; Ivanova et al., 2017; Maciel et al., 2018; Kan et al., 2018; among others).

The basis for the mathematical model applied in roll waves studies generally results from the inclusion of a good rheological model of the fluid in the viscous part of the stress tensor in the momentum equation, providing, along with the conservation of mass, Navier-Stokes equations (for Newtonian fluids) and Cauchy equations (for non-Newtonian fluids).

Thus, the aim of this work is to revisit a roll wave mathematical model based on depth-averaged equations, for a laminar flow of non-Newtonian fluid (Maciel et al., 2013), focusing on two generation criteria for the phenomenon: the minimum Froude number, determined with basis on the temporal linear stability analysis, and the cut-off frequency (spatial stability), defined as the maximum frequency below which roll waves would occur, and above which they would be dampened (Ferreira, 2013). Furthermore, our work also aims to verify if the new generation criteria established for flows of non-Newtonians fluids can be confirmed through numerical simulations performed by a second model with full equations (Fluent software).

Since the instabilities present a spatial-temporal growth, they can be interpreted as a dynamic system, subjected to diverse theoretical and numerical analysis. Numerical simulations were performed with the Fluent 14.5 software (full equations), exhibiting roll waves whose amplitude and wavelength varied in function of the flow Froude number and the cut-off frequency. The results were theoretically and experimentally in accordance with the literature, allowing for validating the criteria for phenomenon generation and control. Later on, we applied such findings in a case study concerning the roll waves generation in the Acquabona basin (Italy).

\section{Considerations on rheology}

Studies concerning rheology precede its own nomenclature, with Hooke and Newton, still in the century XVII, being the first to establish a relation between stress and shearing. The term "rheology" was created by Professor E. C. Bingham, characterizing the study of the deformation and flow of matter. Later on, in 1929, such definition was accepted along with the foundation of the American Society of Rheology (Barnes et al., 1989).

The rheological behavior of the materials is defined in accordance with the relation between forces and deformations.
This relationship can be represented by a mathematical formulation called "rheological equation of state" or "constitutive equation". Thus, the rheological properties are expressed by a mathematical model whose values represent the characteristics of the material (Malkin \& Isayev, 2012).

In order to fully comprehend the rheology of materials, a previous knowledge about the relation between two physical quantities is fundamental: the shear stress and the shear rate, both responsible for classifying the materials as Newtonian and non-Newtonian. Furthermore, it is necessary to understand the composing parameters of such quantities: the viscosity (differential, apparent, complex), which defines the relation between shear stress and shear rate; the yield stress, which refers to the minimum stress required for the fluid to flow; and the flow index, indicative of the linearity or the non-linearity of the shear stress/rate relation.

Rheology can be applied in several areas, from the hemorheology, to the pharmaceutical, chemical, food and construction industries, and in the treatment of the hydrodynamics of natural (or artificial) phenomena with the presence of complex fluids. In this sense, several fields in science can no longer develop without rheological studies - polymers and plastics, for instance, are still the main object of rheological researches (Malkin \& Isayev, 2012).

Recent studies have been focusing on the rheological characterization of mud materials produced by the mining industry, with aims to minimize the impacts of the activity (Boger, 2013; Long et al., 2017). It is important to understand the dynamic behavior of flows of this nature (mudflow) and identify their nondestructive potential (benefits), in order to define methodologies for a sustainable applicability of such material, like in brick production, for example (Buzzo, 2019).

The rheological characterization of mud materials is even more complex due to its non-Newtonian nature. Therefore, more refined rheometric approaches, such as the use of rheometers or consolidated alternative techniques, able to accurately provide the levels of shear stress and shear rate of the analyzed materials, have become mandatory.

In free-surface natural flows like flows of mud and debris, the distinguishing behavior of these materials, characterized by the suspension of mineral-based particles (clay, extended granulometry sands and other particulates) in water, is rheologically described by non-Newtonian models, more specifically the Herschel-Bulkley's (Coussot, 2014). Such model is not only characterized by the nonlinear relation between shear stress and shear rate, but also for the presence of a yield stress and an apparent viscosity, allowing for the occurrence of thixotropic and viscoelastic phenomena (Freydier et al., 2017).

Viscoplastic fluids of similar rheology, like the carbopol gel, are usually employed in physical experimentations carried out in laboratories (Piau, 2007; Chambon et al., 2014). The carbopol gel is a viscoplastic fluid produced from a hydro-dissolvable acrylic polymer, whose rheological characteristics are similar to those of the mud found in mudflows and in dam reservoirs. Analogous to mud, the carbopol gel presents, on determined concentrations, yield stress and has the Herschel-Bulkley model as representative of its rheological properties (Balmforth et al., 2014).

In this context, our research group has been working on the rheometry of different types of fluid, whose rheograms are 
exhibited in Figure 2. It is worth noticing that the pure glycerin (Newtonian), the carbopol gel and the clay mixtures (HerschelBulkley) are the most-employed fluids used in the generation of experimental roll waves.

\section{METHODOLOGY}

\section{Mathematical modelling}

The roll wave mathematical modelling is developed with basis on the classical system of equations of momentum and conservation of mass, in which a proper stress tensor (Newtonian, Binghamian, Herschel-Bulkley, Casson, Carreau, etc) is inserted in the viscous part of the dynamic equation. On the hypotheses of an incompressible and homogenous fluid, in a laminar regime, with null velocity (no-slip condition), in the bottom of a large inclined channel, under the action of gravity, the dimensionless depth-averaged Cauchy system of equations for a non-Newtonian Herschel-Bulkley fluid is given by (Maciel et al., 2013).

Continuity equation:

$$
\frac{\partial h}{\partial t}+\frac{\partial(h \bar{u})}{\partial x}=0
$$

Momentum equation:

$$
\frac{\partial(\bar{u} h)}{\partial t}+\frac{\partial\left(\alpha \bar{u}^{2} h\right)}{\partial x}+\frac{1}{2 F r^{2}} \frac{\partial h^{2}}{\partial x}=h-C-(1-C)\left[\bar{u} h \frac{(1-C)(n+1+n C)}{(h-C)((n+1) h+n C)}\right]^{n}
$$

with length scales: $x^{*}=x / L, h^{*}=h / h_{0}$; velocity scale: $\bar{u}^{*}=\bar{u} / \bar{u}_{0}$; time scale: $t^{*}=\bar{u}_{0} t / L ; F r=\bar{u}_{0} / \sqrt{g h_{0} \cos \theta}$ (Froude number), $C=\tau_{c} /\left(\rho g h_{0} \sin \theta\right)$ (yield stress parameter, $\tau_{c}$ : yield stress), where $h$ is the fluid height, $\bar{u}$ is the mean flow velocity, $x$ is the longitudinal distance along the channel, $t$ is the time, $L$ is the characteristic length, $n$ is the flow index, $\rho$ is the fluid density, $g$ is the gravity acceleration, $\theta$ is the channel slope, $h_{0}$ is the fluid depth, $\bar{u}_{0}$ is the mean velocity in a uniform flow, and $\alpha=\frac{(2 n+1)}{(3 n+2)} \frac{\left[2(n+1)^{2}+C(4 n+3) n\right]}{\left[(n+1)^{2}+2(n+1) n C+n^{2} C^{2}\right]}$ is the momentum coefficient distribution along the depth, in function of $n$ and $C$. Asterisks were omitted in (1) and (2) for notation convenience.

The dimensional mean uniform flow velocity for Herschel Bulkley fluid is calculated by Equation 3 (Maciel et al., 2013).

$\bar{u}_{0}=\frac{n}{n+1}\left(\frac{\rho g \sin \theta z_{0}{ }^{(n+1)}}{k_{n}}\right)^{\frac{1}{n}}\left(\frac{n+1+n C}{2 n+1}\right)$

where: $z_{0}=h_{0}-\tau_{c} / \rho g \sin (\theta)$.

Through Equations 1 and 2, it is possible to evaluate the above-mentioned scheme as a dynamic system of the phenomenon, allowing for the use of the stability analysis technique. For such analysis, an infinitesimal disturbance of small amplitude is added to the uniform flow $(h, u)=(1,1)$, which is given by: $h(x, t)=1+H(x, t)$ and $u(x, t)=1+U(x, t)$, with $H(x, t)$ and $U(x, t)<<1$.

\section{Linear stability analysis}

The linear stability theory is a tool that allows us to obtain important information about the dynamic system, such as the growth rate and the propagation velocity of instabilities. Through this method, widely discussed by Briggs (1964), Ng \& Mei (1994), Maciel et al.

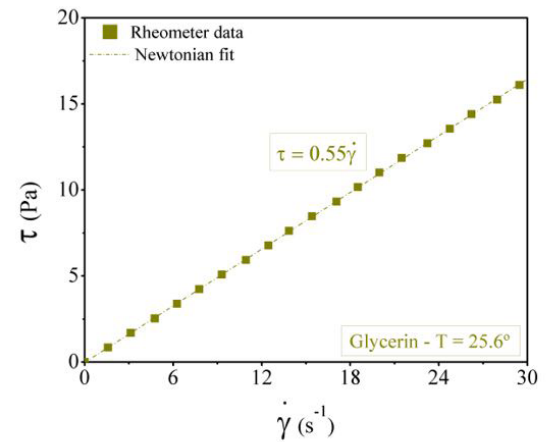

(a)

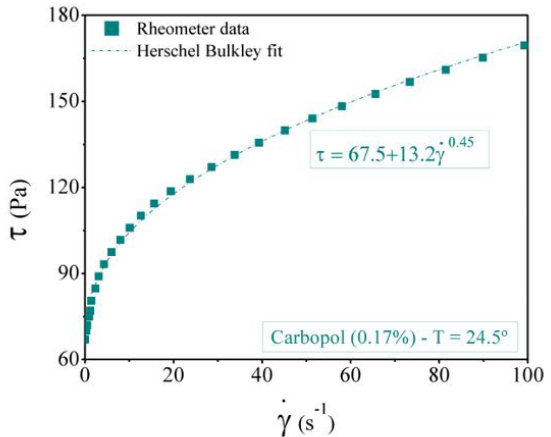

(b)

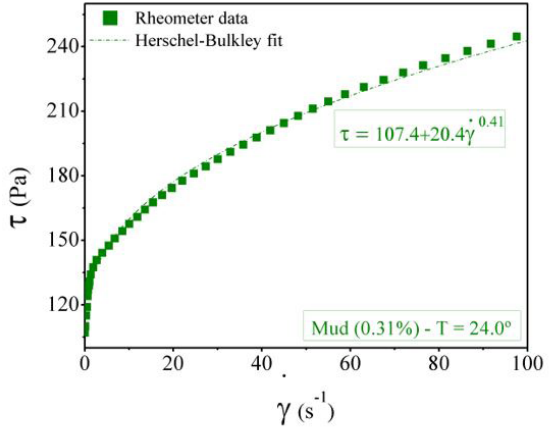

(c)

Figure 2. Flow curve of the fluids analyzed in the generation of experimental roll waves: (a) glycerin, (b) carbopol and (c) mud. 
(2013), it is possible to characterize the necessary conditions for the generation of instabilities. Di Cristo \& Vacca (2005) used this theory to evaluate the convective nature of roll waves instabilities, i.e. to demonstrate how waves can appear and grow in time and space only if the flow conditions are favorable. The aim of this section is to determine the dispersion equation for the system (Equation 1 and 2) and analyze how infinitesimals disturbances $(H(x, t)$ and $U(x, t))$ in the height $h(x, t)$ and in the mean flow velocity $\bar{u}(x, t)$ behave. Knowing the periodicity of the solution, the disturbance can be described as $H(x, t)=\hat{H} e^{i(k x-\omega t)}$, where $\hat{H}$ is the magnitude (constant), $k$ is the wavenumber, and $\omega$ is the frequency. Parameters $k$ and $\omega$ are complex numbers defined as: $\omega=\omega_{r}+i \omega_{i}$ and $k=k_{r}+i k_{i}$, with $k_{r}$ (real part of $k$ ) being the wavenumber, $\omega_{r}$ (real part of $\omega$ ), the frequency, and $k_{i}$ and $\omega_{i}$, the amplification rates, where $\omega_{i}>0$ indicates a temporal amplification and $k_{i}<0$ indicates a positive spatial amplification in the $x$ direction (Gaster, 1962). The dispersion equation (Equation 4) can be obtained by solving the disturbed system for $H(x, t)$.

$$
\omega^{2}-[2 \alpha k-n(1-C) i] \omega+\left(\alpha-\frac{1}{F r^{2}}\right) k^{2}-i \frac{(n+1)(2 n+1)}{(n+1+n C)} k=0
$$

\section{First criterion}

The temporal linear stability analysis is determined by solving the dispersion equation (Equation 4), whose incognita is $\omega$, while considering $k_{i}=0$. Therefore, the first criterion for instabilities generation is obtained (Equation 5). In order for the disturbances to propagate downstream and amplify themselves, the Froude number must be greater than the threshold value $F r_{\text {min }}$, as described in detail by Maciel et al. (2013).

$$
F r>F r_{\min }=\frac{\vartheta}{\sqrt{\varphi^{2}-2 \alpha \varphi \vartheta+\alpha \vartheta^{2}}}
$$

where:

$\varphi(n, C)=\frac{(n+1)(2 n+1)}{(n+1+n C)}$

$\vartheta(n, C)=n(1-C)$

\section{Second Criterion}

By its turn, the spatial stability is carried out aiming to examine a critical condition related to the disturbance frequency. Thus, based on the dispersion equation (Equation 4) and considering $k=k_{r}+i k_{i}$ and $\omega_{i}=0, k\left(\omega_{r}\right)$ is given by Equation 6 (Ferreira, 2013).

$$
k\left(\omega_{r}\right)=\frac{1}{\left(\alpha-\frac{1}{F r^{2}}\right)}[(2 \alpha \omega+\varphi i) \pm \sqrt{c+d i}]
$$

with:

$$
\begin{aligned}
& c=4 \omega^{2}\left(\alpha^{2}-\alpha+\frac{1}{F r^{2}}\right)-\varphi^{2} \\
& d=4 \omega\left(\alpha \varphi-\alpha \vartheta+\frac{\vartheta}{F r^{2}}\right)
\end{aligned}
$$

After solving Equation 6, for $k_{r}>0$, we obtained Equation 7 and Equation 8, respectively related to the cutoff frequencies $\left(\omega_{c}, f_{c}\right)$.

$$
\omega<\omega_{c}=\frac{1}{2 \alpha} \sqrt{a b s\left[\left(\alpha-\frac{1}{F r^{2}}\right) \vartheta^{2}-2 \alpha \vartheta \varphi\right]} \text { (dimensionless) }
$$

or yet

$$
f<f_{c}=\left(\frac{\omega_{c}}{2 \pi}\right) \frac{\bar{u}_{0}}{h_{0}} \text { (dimensional) }
$$

More details about the second criterion are presented in Appendix A.

\section{Numerical simulations}

It is worth noticing that numerical simulation of the Equations 1 and 2 (Maciel et al. 2013), in which the first generation criterion is satisfied (minimum Froude or Reynolds number), have already been widely carried out by various authors (Maciel \& Lledo, 1999, Balmforth \& Liu, 2004, Di Cristo et al., 2013b). The significant contribution brought by the new mathematical model (Equations 1 and 2) resides in including the complexity of the Herschel-Bulkely viscoplastic rheology (three-parameter rheological model) in the viscous tensor, which is associated to the establishment of the supplementary criterion (cut-off frequency). Our results show that the minimum Froude number is necessary, but not enough to generate the phenomenon.

Thus, this technical note aims to verify if a full equations model is able to validate the generation criteria previously established, and to examine if the roll waves retain the same properties.

The numerical simulations were performed within the ANSYS Fluent 14.5 software. The full equations (of continuity and momentum) were discretized through the finite volume method. The geometry and mesh were elaborated using the ANSYS Design Modeler and ANSYS Meshing, respectively. The mesh was constituted of 193.200 rectangular elements (with spatial refinement $D x \leq 5 \times D y$ near of the inlet of channel) and all simulations were performed with a fixed time step of $0,0001 \mathrm{~s}$, small enough to guarantee numerical stability through the Courant-FriedrichsLewy (CFL) condition $(\mathrm{CFL}<0.25)$. Figure 3 presents the applied boundary conditions and the employed mesh (it is important to observe that $h_{0}$ is the normal depth of the channel and $2 h_{0}$ is the region with the refined mesh). The selected meshing was used in the generation of roll waves due to its well-refinement, and its capability in assuring numerical convergence and providing theoretical-numerical results in agreement with the uniform regime (normal depth, velocity profile and shear rate). The numerical schematization is summarized in Table 1.

Given the necessity to numerically detect the interface between the test fluid and the air, we utilized the VoF interface tracking method (Hirt \& Nichols, 1981; Ferreira et al., 2015; Issakhov \& Zhandaulet, 2020). In order to apply this technique, we considered the immiscibility of both fluids, and introduced the volume fraction scalar variable to track the interface.

The VoF technique adds a new scalar diffusion-advection equation, coupled with the continuity and momentum equations, 


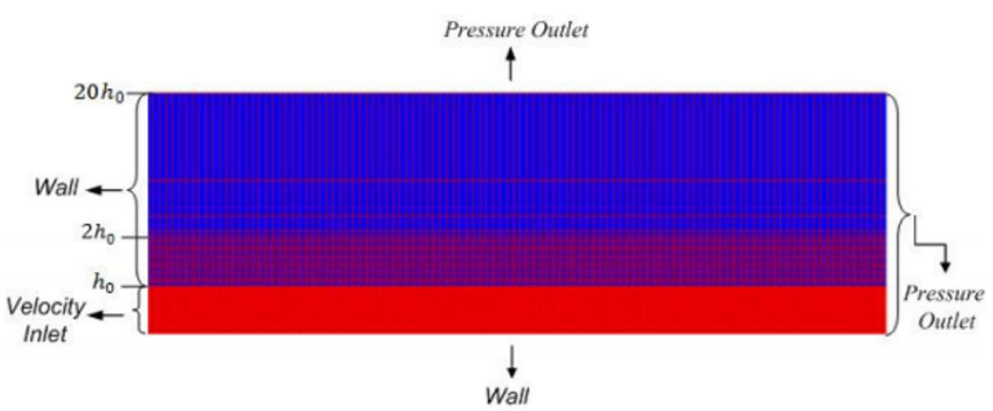

(a)

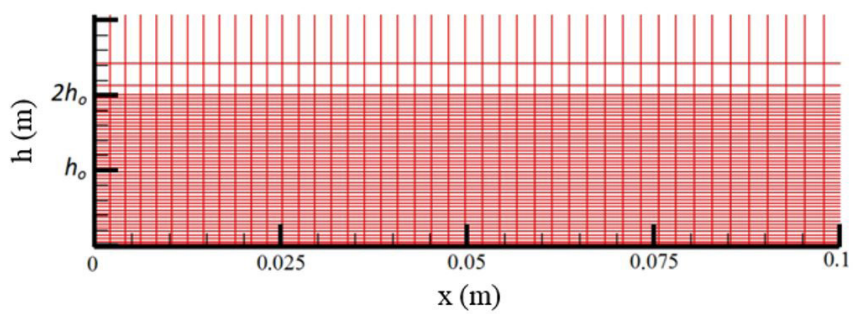

(b)

Figure 3. Numerical mesh used for roll wave simulation: (a) boundary conditions and (b) grid details.

Table 1. Employed Numerical schemes in roll wave simulation.

\begin{tabular}{cc}
\hline Multiphase model & VoF \\
\hline Time & Unsteady \\
& Second Order Implicit \\
Viscous model & Laminar \\
Pressure-velocity coupling & Simplec \\
Pressure & Presto \\
Momentum & Third Order MUSCL \\
Volume fraction & Modified HRIC \\
\hline
\end{tabular}

to obtain the volume fraction field in order to track the interface between test fluid and air. The Modified High Resolution Interface Capturing (HRIC) scheme is used in this work to discretize the volume fraction equation. In order to numerically disturb the uniform flow, we employed a User-Defined Function (UDF) applied to the velocity inlet of the channel, dependent on the imposed disturbance frequency (Equation 9):

$V=\bar{u}_{0}\left[1+B \sin \left(\frac{2 \pi t}{T}\right)\right]$

where $V$ is disturbed mean flow velocity with period $T(f=1 / T)$ and magnitude $B$ (in the order of $1 / 1000$ ).

\section{RESULTS AND DISCUSSIONS}

In order to analyze the occurrence of roll waves phenomena and evaluate its generation criteria, numerical simulations for Newtonian, power-law and Herschel-Bulkley fluid flow cases are presented in this section. Data were gathered from previous works which observed and/or simulated flows with roll waves generation. For the Newtonian case, Fiorot et al. (2015) experimentally observed and measured roll waves in pure glycerin flowing down an inclined channel of $0.30 \mathrm{~m}$ x $0.15 \mathrm{~m}$ x $2.50 \mathrm{~m}$ long. For the power-law case, $\mathrm{Ng} \&$ Mei (1994) observed roll waves. The Herschel-Bulkley case was simulated in the same conditions of the power-law case, adding a low yield stress value to the power-law fluid. In this technical note, all numerical tests were performed in a $6 \mathrm{~m}$ long numerical channel. Subsection Uniform flow presents the simulations for the three fluids. Subsection Roll wave generation shows the results for a disturbed uniform flow to verify the roll wave generation. The properties of the fluids, of the flows and roll waves simulated are summarized in Table 2 . Finally, we present a qualitative analysis of roll wave generation in the Acquabona Case.

\section{Uniform flow simulation}

The case studies gathered in Table 2 were initially simulated without imposing any disturbances in the fluid, so it would be possible to verify some of the properties of the uniform flow, such as velocity profiles and shear rates. The simulations performed by the Fluent software (full equations) were then confronted with the mathematical model (Equations 1 and 2), for both the velocity profile and the shear rates, as it can be seen in Figure 4.

It can be noticed that the uniform flow simulations present a good agreement with the results of the mathematical model. When it comes to the simulations related to Herschel-Bulkley fluids (with the presence of a yield stress), the occurrence of a plug becomes evident, i.e., the depth from the free surface in which the shear rate is null (fluid flowing as a "solid body"). By comparing the flow results provided by the Power-law and the Herschel-Bulkley fluids, it can be seen that the presence of a yield stress culminates in lower shear rates.

\section{Roll wave generation}

Following the parameters set in Table 2, both generation criteria were checked for the three types of fluid: Newtonian, Powerlaw and Herschel-Bulkley. The first criterion was to verify a Froude number $F r>F r_{\text {min }}$, which depends on the fluid characteristics and 

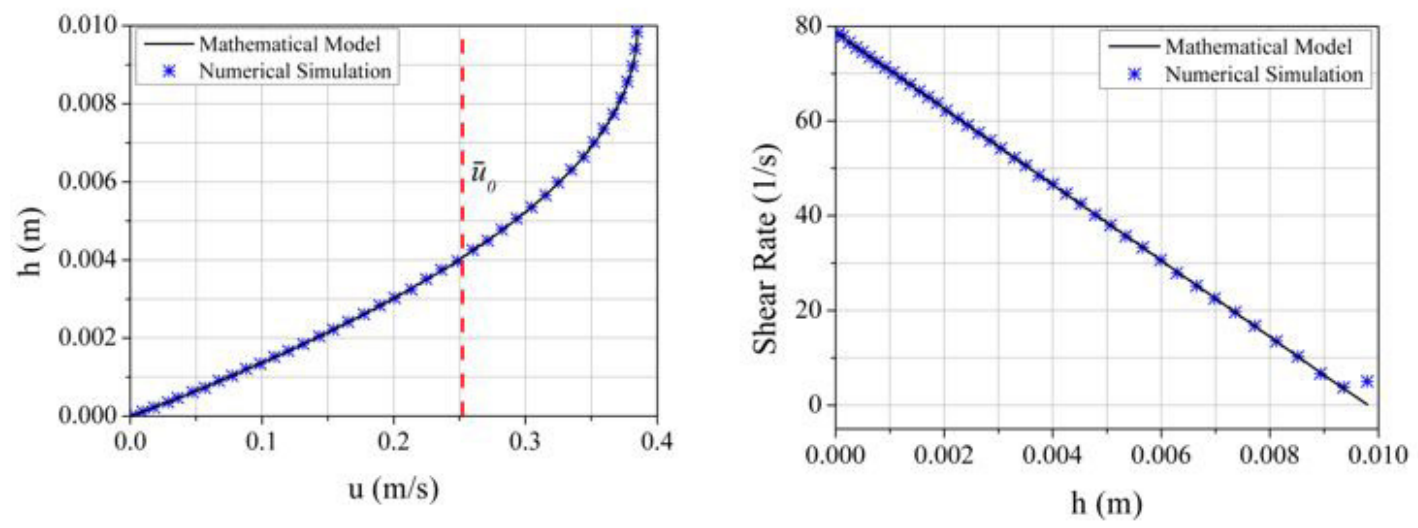

(a)
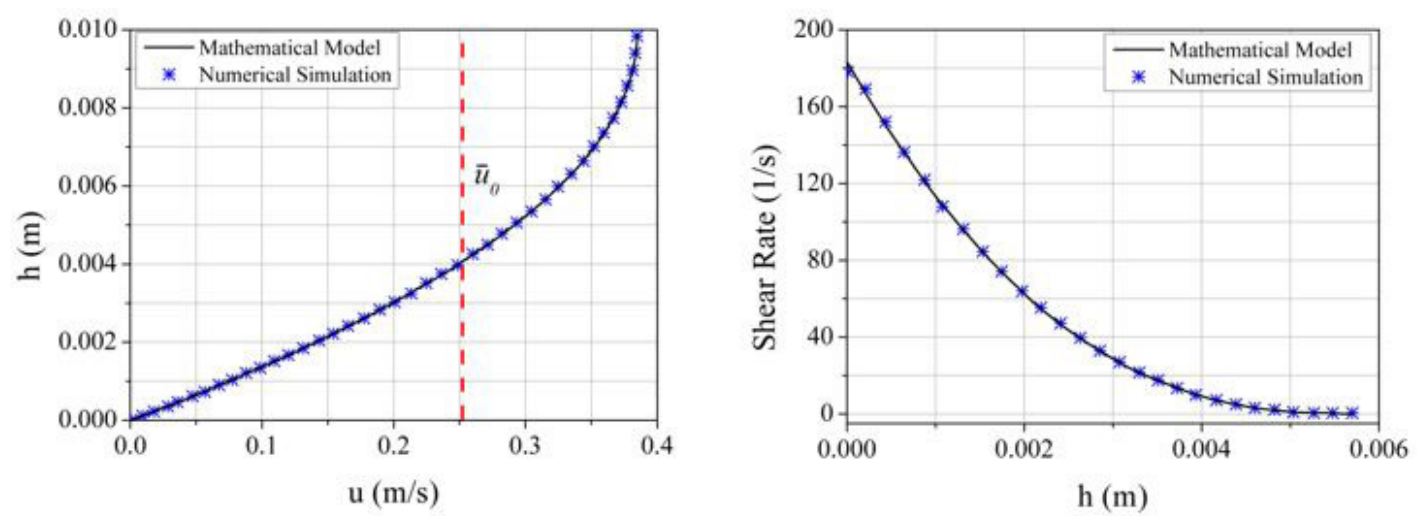

(b)
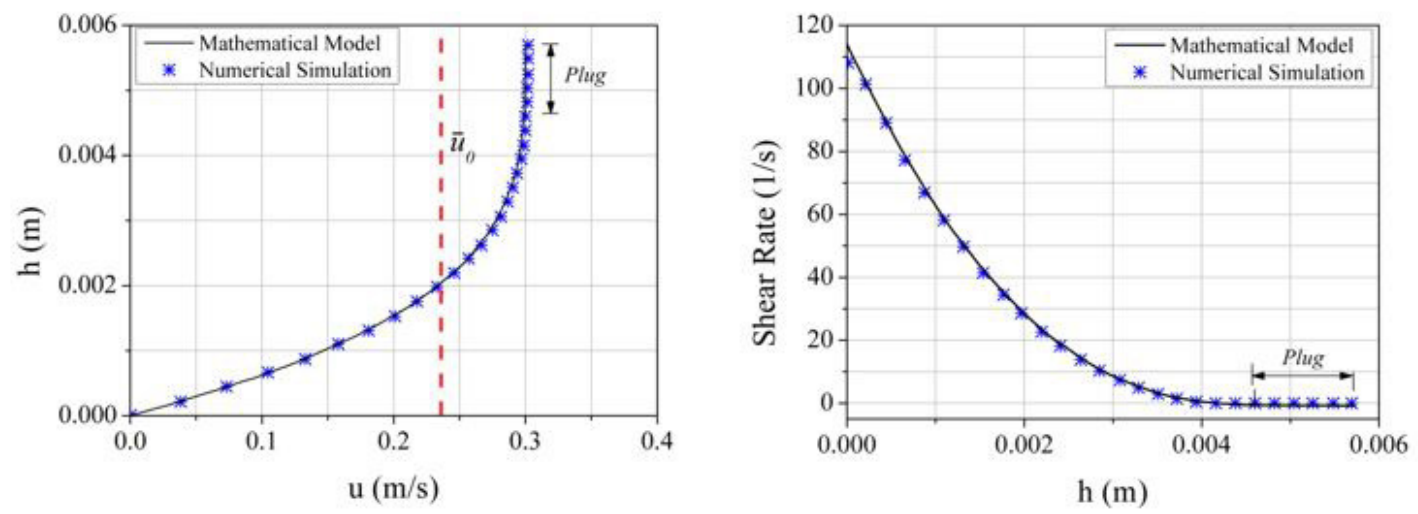

(c)

Figure 4. Numerical simulation versus mathematical model concerning the velocity profiles and the shear rates of the uniform flow for: (a) Newtonian, (b) Power-law and (c) Herschel-Bulkley fluids.

on the flow dynamics (Equation 5). Should the first condition be satisfied, the second criterion is then tested. Not every disturbance frequency will be able to produce permanent roll waves.

The range of frequencies that favors the phenomenon occurrence depends on the rheological properties of fluid and on the Froude number, as shown in Equation 7 and Equation 8. Table 2 summarizes the properties of all test fluids, the values concerning the generation criteria for stabilized roll waves $\left(F r_{\text {min }}\right.$, $\omega_{c}$, and $f$ ), and the main features of the experimentally-simulated permanent roll waves.

Through the data presented in Table 2, it can be seen that the Froude number is higher than the minimum necessary for all tests. It can also be observed that the cut-off frequency decreases each time we added a non-Newtonian effect ( $n$ and $\tau_{c}$ ). In order to verify the validity of the cut-off frequency criterion, simulations were performed at various disturbance frequencies. 
Table 2. Fluid properties, minimum conditions for roll wave generation, wave height $(\Delta \boldsymbol{h})$, wavelength $(\lambda)$ and celerity $\left(\boldsymbol{U}_{\text {num }}\right)$.

\begin{tabular}{|c|c|c|c|c|c|c|c|}
\hline Fluid and Flow Properties & \multicolumn{3}{|c|}{ Newtonian } & \multicolumn{2}{|c|}{ Power-law } & \multicolumn{2}{|c|}{ Herschel-Bulkley } \\
\hline$\tau_{c}(P a)$ & \multicolumn{3}{|c|}{0} & \multicolumn{2}{|c|}{0} & \multicolumn{2}{|c|}{$0.20^{(1)}$} \\
\hline$K_{n}\left(\right.$ Pa.s $\left.^{n}\right) /$ & \multicolumn{3}{|c|}{0.212} & \multicolumn{2}{|c|}{0.14} & \multicolumn{2}{|c|}{0.14} \\
\hline \multicolumn{8}{|l|}{$\mu($ Pa.s $)$} \\
\hline$n$ & \multicolumn{3}{|c|}{1.00} & \multicolumn{2}{|c|}{0.40} & \multicolumn{2}{|c|}{0.40} \\
\hline$C$ & \multicolumn{3}{|c|}{0} & \multicolumn{2}{|c|}{0} & \multicolumn{2}{|c|}{0.1774} \\
\hline$\alpha$ & \multicolumn{3}{|c|}{1.2} & \multicolumn{2}{|c|}{1.125} & \multicolumn{2}{|c|}{1.103} \\
\hline$h_{0}(m)$ & \multicolumn{3}{|c|}{0.0098} & \multicolumn{2}{|c|}{0.0057} & \multicolumn{2}{|c|}{0.0057} \\
\hline $\bar{u}_{0}(m / s)$ & \multicolumn{3}{|c|}{0.256} & \multicolumn{2}{|c|}{0.235} & \multicolumn{2}{|c|}{0.123} \\
\hline$L_{\min }(m)_{(2)}$ & \multicolumn{3}{|c|}{0.45} & \multicolumn{2}{|c|}{1.26} & \multicolumn{2}{|c|}{1.35} \\
\hline $\mathrm{Fr}$ & \multicolumn{3}{|c|}{0.830} & \multicolumn{2}{|c|}{0.985} & \multicolumn{2}{|c|}{0.531} \\
\hline$F r_{\text {min }}$ & \multicolumn{3}{|c|}{0.577} & \multicolumn{2}{|c|}{0.298} & \multicolumn{2}{|c|}{0.218} \\
\hline $\operatorname{Re}$ & \multicolumn{3}{|c|}{14.58} & & & & \\
\hline$f_{c}(H z)$ & & 4.82 & & & & & \\
\hline$\omega_{c}$ & & 1.163 & & & & & \\
\hline W/are heiobt and wavelenoth & & equencies & & Freq & $(\mathrm{Hz})$ & Frequ & $(\mathbf{H z})$ \\
\hline wave netgit and waverefigen & 1.0 & 3.0 & 4.0 & 0.8 & 1.0 & 0.8 & 1.0 \\
\hline$\omega_{c}$ & 0.241 & 0.723 & 0.965 & 0.121 & 0.152 & 0.232 & 0.291 \\
\hline$\Delta h(m)$ & 0.0064 & 0.003 & 0.0011 & 0.0024 & 0.0021 & 0.0016 & 0.0009 \\
\hline$\lambda(m)$ & 0.7500 & 0.210 & 0.1500 & 0.6290 & 0.5030 & 0.5300 & 0.3500 \\
\hline$U_{\text {num }(\mathrm{m} / \mathrm{s})}$ & 0.750 & 0.630 & 0.600 & 0.5032 & 0.5030 & 0.424 & 0.350 \\
\hline
\end{tabular}

(1) Value attributed in the numerical test. ${ }^{(2)}$ All minimal channel lengths $L_{\text {min }}$ (Di Cristo et al., 2013a) were verified.

For the Newtonian fluid, the tested disturbance frequencies were $0.5,1,3,4$ and $6 \mathrm{~Hz}$, and the results of the numerical simulations are shown in Figure 5.

It can be seen that at disturbance frequencies higher than $4.82 \mathrm{~Hz}$, the waves dampened, i.e. should the disturbance frequency be above the critical or cut-off frequency (Table 2), there is no occurrence of roll waves. The same findings are also true for the Power-law $\left(n=0.4 ; \tau_{c}=0\right)$ and the Herschel-Bulkley $\left(n=0.4 ; \tau_{c}=0.2 \mathrm{~Pa}\right)$ models, at disturbance frequencies of $0.8,1.0,2.0$ and $3.7 \mathrm{~Hz}$, as shown in Figure 6. As the disturbance frequency increases, rollwave development initially shuts off in the Herschel-Bulkley fluid and later on in the Power-law fluid.

Furthermore, an increase in the main properties of the roll waves (amplitude, length and propagation velocity) can be noticed as the generating frequencies lessen, in both Newtonian and non-Newtonian cases.

As far as the roll wave profile is concerned, it is possible to verify that low-frequency waves are more sharply, with characteristics similar to those of shock waves, as experimentally verified in Newtonian and non-Newtonian laminar flows (Fiorot et al., 2015, Maciel et al., 2017, Cunha, 2017). Such finding indicates that the disturbance frequency is an important parameter in the generation and in the characterization of roll waves. However, it is necessary to point out that the tests were exclusively carried out in laminar flows, as indicated by the Reynolds number (Table 2).

\section{Qualitative analysis of the roll wave generation} criteria applied in the Acquabona Case

The Acquabona drainage basin, in Italy, drains off into a $1600 \mathrm{~m}$ long channel, and its monitoring system usually registers debris flows with the presence of wavefronts (pulsating regime). Thus, phenomena like the roll wave can be conveniently recorded through a series of monitoring stations installed along the channel, geophone sensors at its bottom, and ultrasonic sensors set up in predetermined spots, allowing for an accurate measurement of the depth of flow in function of time. According to Zanuttigh \& Lamberti (2007), it is possible to confirm the presence of wavefronts and measure their amplitudes and propagation velocities. As an example of qualitative exploratory research, on July $25^{\text {th }}$ and $27^{\text {th }}$, 1998 and on August $17^{\text {th }}$ of the same year, rainfall and depth-offlow measurements were carried out in Acquabona. On August $17^{\text {th }}$, the flow lasted for approximately 38 minutes, registering more than 15 different wave peaks at measuring station number 3. The maximum depth was of $1.8 \mathrm{~m}$ and the front velocity was estimated in $7.7 \mathrm{~m} / \mathrm{s}$, (Berti et al., 2000). Figure 7 exhibits registers of the depth assessed in function of time.

This event (August $17^{\text {th }}, 1998$ ) has been explored both in the characterization of the flowing fluid rheological properties and in the search for models that agreeably represent the phenomenon (Berti et al., 2000; Zanuttigh \& Lamberti, 2007; Fiorot et al., 2018). The waves identified by the letters A, B, C, D, and E, 

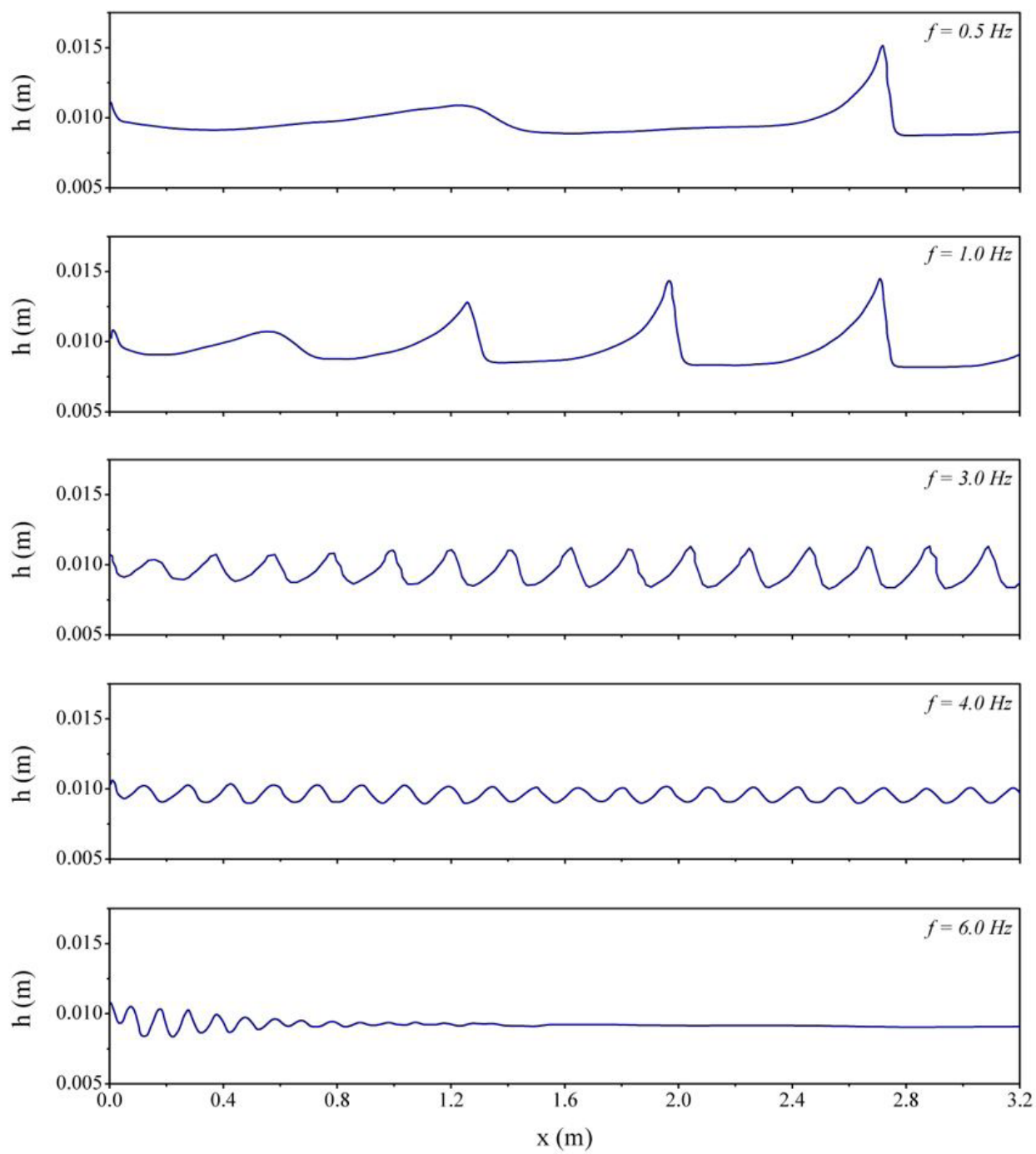

Figure 5. Numerical simulations for the Newtonian fluid at different disturbance frequencies: 0.5, 1, 3. 4 and $6 \mathrm{~Hz}$. Damping effect is observed when the frequency is higher than the cut-off frequency.

inside the shaded region in Figure 7, present similar amplitudes and periods, distinguishing themselves from the other waves. Fiorot et al. (2018) explored the idea that the referenced sequence of waves could have formed a roll-wave pattern, since they were able to verify the ability of the mathematical model established by Maciel et al. (2013) to determine wave amplitudes and their flagrant dependency on the rheological properties of the fluid. Taking into account the type of sediment and the granulometry, in accordance with the method proposed by Malet et al. (2003) and the technique established by Fraccarollo \& Papa (2000) for determining the yield stress, a smaller error was obtained in the roll-wave amplitude (error of $-13 \%$, excluding D peak). Further details are discussed by Fiorot et al. (2018). Table 3 exhibits the cut-off frequency and the minimum Froude number required for roll wave generation, based on the rheological parameters and on the normal depth of flow estimated for the Acquabona case.

It can be observed in Table 3 that the average Froude number of the flow is higher than the minimum Froude number required for roll wave generation. Additionally, the cut-off frequency indicates that waves generated in the Acquabona case were characterized by low frequencies, while exhibiting high amplitudes and long periods $\mathrm{T}$ (in the order of $100 \mathrm{~s}$ ), as it can be seen in Figure 7.

Lastly, Figure 8 presents the behavior of the dimensionless cut-off frequency $\left(\omega_{c}\right)$ in function of the Froude number, using the simulated data of the Newtonian and the non-Newtonian fluids (Table 2) and those of the Acquabona case (Table 3). The generation criteria discussed in this technical note are even more distinguishable in Figure 8, which visually details the domains for roll wave generation and non-generation with basis on the $\mathrm{Fr}$ and $\omega_{c}$ parameters.

Based on Figure 8, it can be noticed that the domain for roll wave generation related to the first criterion $\left(F r_{\text {min }}\right)$ is favored by the non-Newtonian trait of the fluid, which allows for the generation of roll waves even at low Froude numbers. It is important to emphasize, however, that this analysis refers to laminar flows. Based on the literature, it can be seen that, in order for roll waves to be generated, the Froude number should be higher than 0.577 for Newtonian flows under laminar regime (Benjamin, 1957), and higher than 2.0 for turbulent regimes (Jeffreys, 1925). 

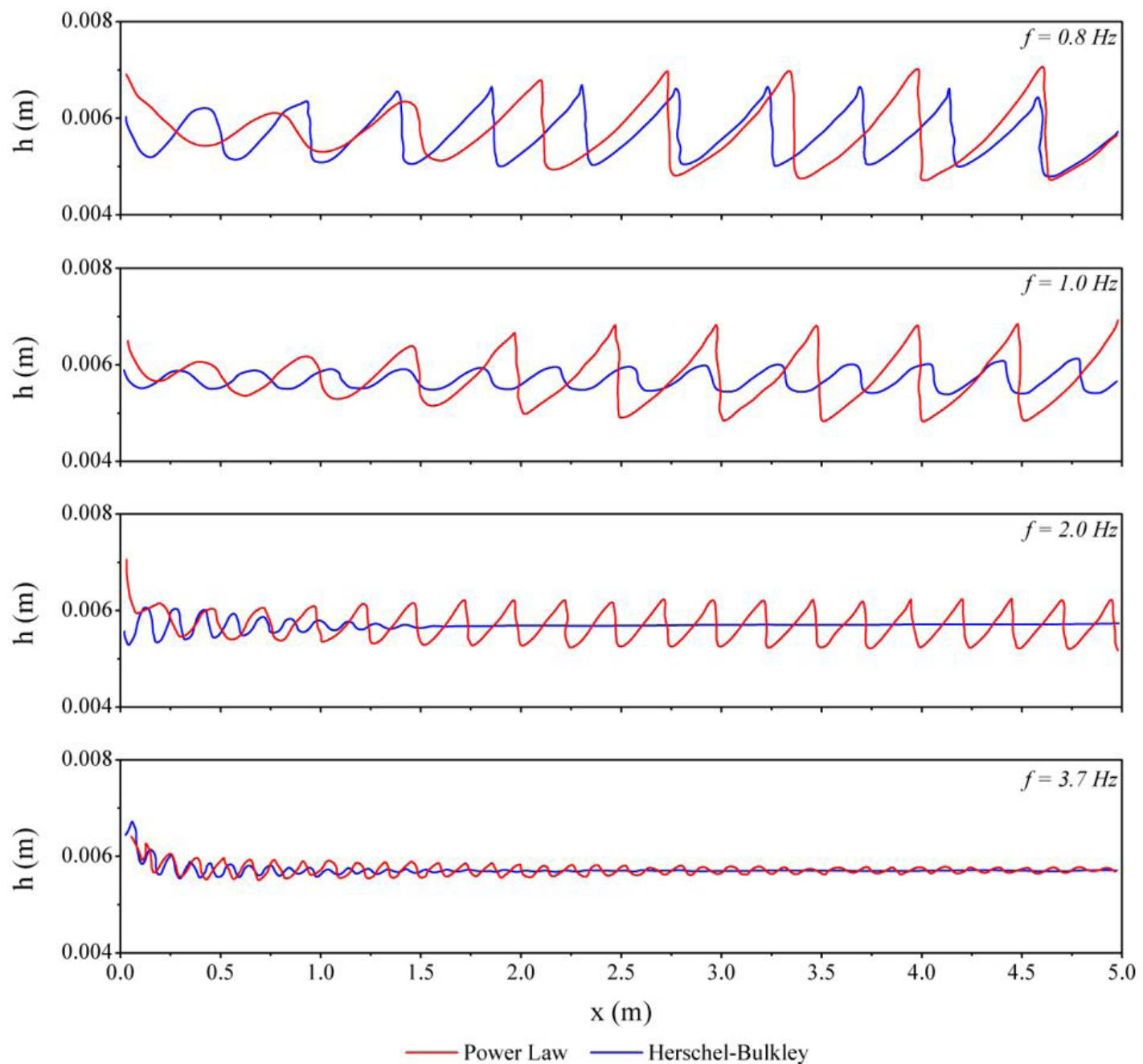

Figure 6. Numerical simulations for non-Newtonian fluids at different disturbance frequencies: 0.8, 1.0, 2.0 and 3.7 Hz. Damping effect is observed when the frequency is higher than the cut-off frequency.

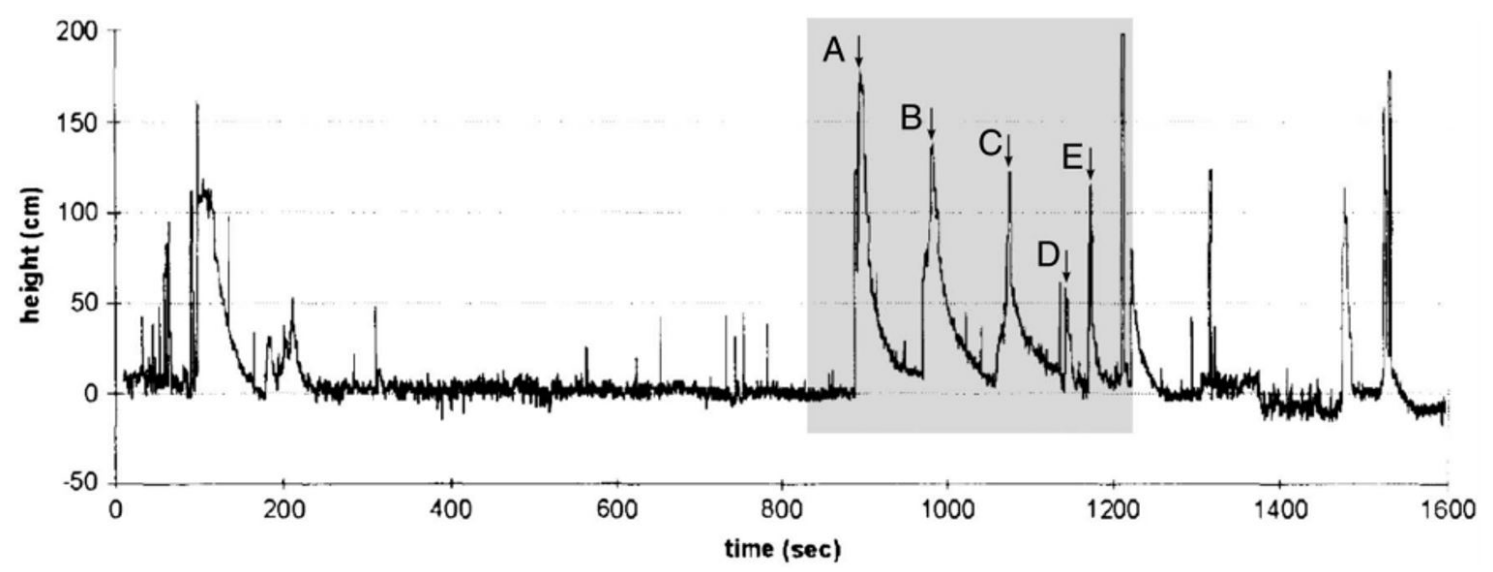

Figure 7. Depths assessed on August 17 $7^{\text {th }}, 1998$ (Berti et al., 2000). The highlighted wave train indicates a possible roll wave formation.

When it comes to the cut-off frequency, it can be observed that the non-Newtonian property of the fluid favors the generation of low-frequency roll waves. Moreover, should the Froude number tend to infinity, the cut-off frequency is asymptotic, exhibiting lower values than those for low Froude numbers. For the instances discussed in this work, the limit superior of the cut-off frequency is given by the Newtonian case and the limit inferior, by the Acquabona case (HerschelBulkley fluid), whose elevated rheological properties lead to low characteristic frequencies $\left(\omega_{c}, f_{c}\right)$. 
Table 3. Fluid properties and minimum conditions for roll wave generation in Acquabona case (Fiorot et al., 2018).

\begin{tabular}{cccc}
\hline \multicolumn{2}{c}{ Herschel-Bulkley model } & \multicolumn{2}{c}{ Fluid and Flow properties } \\
\hline$\tau_{c}(\mathrm{~Pa})$ & 762 & $\theta($ degrees $)$ & 7 \\
$k_{n}\left(\mathrm{Pas}^{n}\right)$ & 458 & $h_{0}(\mathrm{~m})$ & 0.83 \\
$n$ & 0.3 & $\alpha$ & 1.06 \\
- & - & $\rho_{\text {mixture }}\left(\mathrm{kg} / \mathrm{m}^{3}\right)$ & 2,039 \\
- & - & $\mathrm{C}$ & 0.377 \\
- & - & $\bar{u}_{0}(\mathrm{~m} / \mathrm{s})$ & 3.08 \\
- & - & $F r$ & 1.08 \\
- & - & $R e$ & 53.20 \\
\hline & - & $f\left(H_{z}\right)$ & $\cong 0.01$ \\
\hline
\end{tabular}

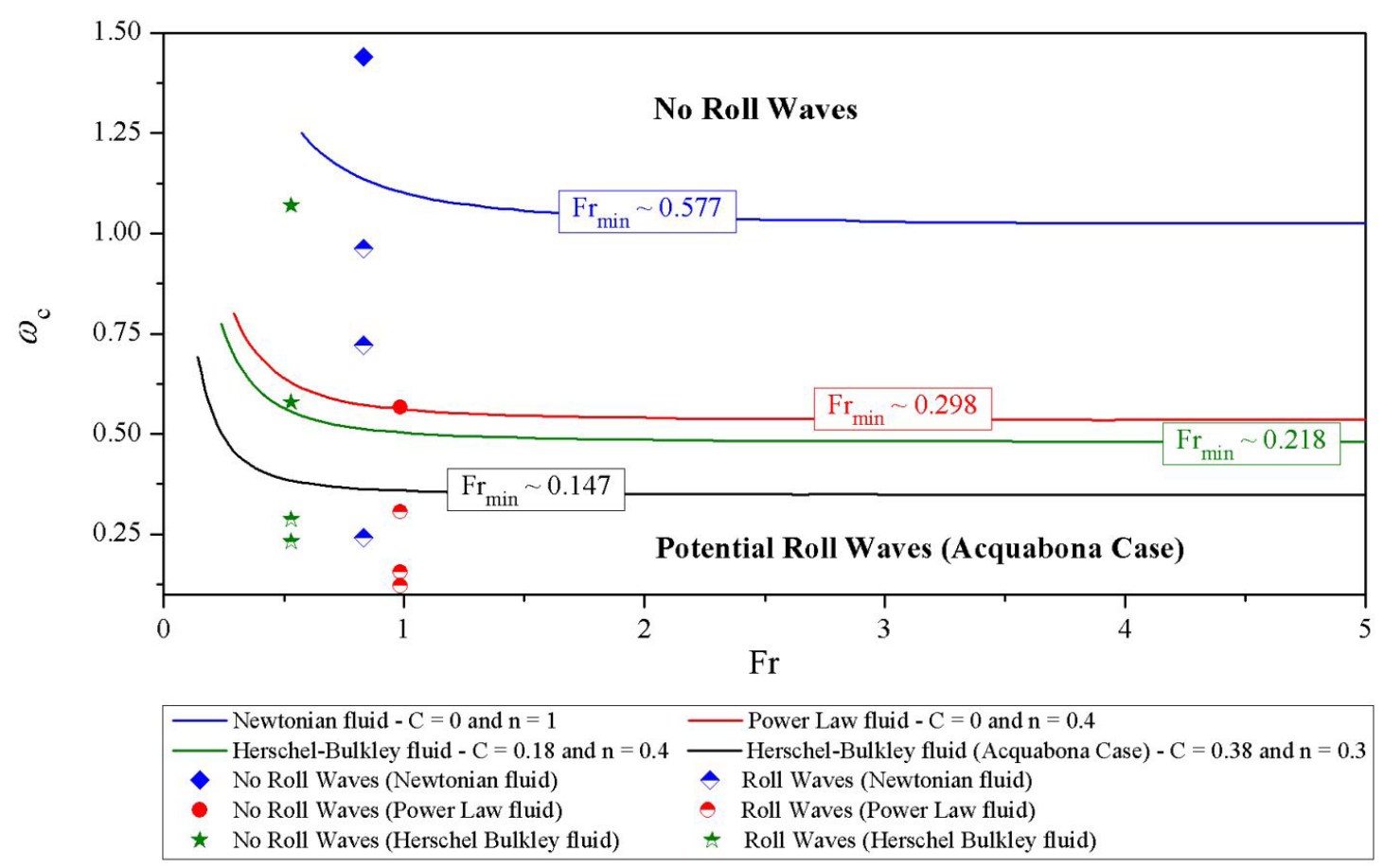

Figure 8. Behavior of the cut-off frequency as a function of the Froude number for the different fluid rheologies evaluated in this work (Table 2) and in the Acquabona case (Table 3).

\section{FINAL CONSIDERATIONS}

In this work, we presented the theoretical and numerical results of experimental roll waves, generated by a disturbance imposed onto the uniform flow. In order for such disturbances develop into roll waves, two criteria must be met: the first one is associated with the ratio of inertial and gravitational forces (Froude number), and the second is related to the disturbance frequency.

The results obtained through numerical simulations show a good agreement towards the analytical results for different kinds of fluid. It should be noticed that, although the simulations were performed under a favorable domain for roll wave generation $\left(F r>F r_{m i n}\right)$, their propagation and development also depend on the disturbance frequency. This proves that the first criterion $\left(F r_{\text {min }}\right)$ is necessary but not sufficient for generating the phenomenon, even if indicates that low Froude numbers are adequate for the occurrence of roll waves in non-Newtonian fluids. In fact, the cut-off frequencies of the non-Newtonian fluids are lower than those of the Newtonian fluids.

Based on the numerical results, it could be verified that, for a given fluid, the roll wave amplitudes and lengths decreased along with the disturbance frequency, which is in good agreement with the experimental observations (Cunha, 2017). Moreover, since the tests were carried out under distinct dynamic conditions and their main purpose was to numerically test the roll wave generation criteria, the numerical observations vouch for the fact that the non-Newtonian property of the fluid always favors the generation of anticipated roll waves with high amplitudes and longer lengths. Such effects can also be observed in simulations involving mud fluids flows or describing debris flows with the presence of roll waves (Maciel, 2002). 
As previously seen, the criteria for roll wave generation were determined through the linear stability analysis of a depthaveraged model (Maciel et al., 2013), whose results (first and second criteria) were also validated, without any incongruity, by the numerical simulations performed with full equations (Fluent software). Such findings corroborate the initial proposal of this technical note.

Finally, based on both models (Maciel et al., 2013 and Fluent software), we were able to verify the generation of roll waves, by assessing their occurrence on open-channel flows, a phenomenon that usually increases the flow energy and, consequently, the likelihood to cause greater damage to the civil infrastructure and to the people of affected communities.

\section{ACKNOWLEDGEMENTS}

The authors would like to thank FAPESP - Fundação de Amparo à Pesquisa do Estado de São Paulo (Number 2015/25.518-8 and 2020/07822-0) and CNPq - Conselho Nacional de Desenvolvimento Científico e Tecnológico (Number 44.9550/2014-4) for providing the financial support for this research.

\section{REFERENCES}

Arai, M., Huebl, J., \& Kaitna, R. (2013). Occurrence conditions of roll waves for three grain-fluid models and comparison with results from experiments and field observation. Geophysical Journal International, 195(3), 1464-1480. http://dx.doi.org/10.1093/gji/ ggt352.

Aranda, A., Amigo, N., Ihle, C., \& Tamburrino, A. (2016). Digital image correlation applied to the calculation of the out-of-plane deformation induced by the formation of roll waves in a nonNewtonian fluid. Optical Engineering, 55(6), 064101. https://doi. org/10.1117/1.OE.55.6.064101.

Aydin, T. B., Torres, C. F., Karami, H., Pereyra, E., \& Sarica, C. (2015). On the characteristics of the roll waves in gas-liquid stratifies-wavy flow: a two-dimensional perspective. Experimental Thermal and Fluid Science, 65, 90-102. http://dx.doi.org/10.1016/j. expthermflusci.2015.02.013.

Balmforth, N. (2011). Roll waves in a concrete channel in Lions, Vancouver. Retrieved in 2020, October 15, from http://www.math.ubc. $\mathrm{ca} / \sim$ njb/Research/rollo.htm

Balmforth, N. J., \& Liu, J. J. (2004). Roll waves in mud. Journal of Fluid Mechanics, 519, 33-54. http://dx.doi.org/10.1017/ S0022112004000801.

Balmforth, N. J., Frigaard, I. A., \& Ovarlez, G. (2014). Yielding to stress: recent developments in viscoplastic fluid mechanics. Annual Review of Fluid Mechanics, 46(1), 121-146. http://dx.doi. org/10.1146/annurev-fluid-010313-141424.

Barnes, H. A., Hutton, J. F., \& Walters, K. (1989). An introduction to rheology. Amsterdam: Elsevier.
Bazargan, J., \& Aghebatie, B. (2015). Numerical analysis of roll waves in chutes. Water Science and Technology: Water Supply, 15(3), 517-524. http://dx.doi.org/10.2166/ws.2014.136.

Benjamin, T. B. (1957). Wave formation in laminar flow down an inclined plane. Journal of Fluid Mechanics, 2(06), 554-574. http:// dx.doi.org/10.1017/S0022112057000373.

Berti, M., Genevois, R., LaHusen, R., Simoni, A., \& Tecca, P. R. (2000). Debris flow monitoring in the Acquabona watershed on the Dolomites (Italian Alps). Physics and Chemistry of the Earth. Part B: Hydrology, Oceans and Atmosphere, 25(9), 707-715. http://dx.doi. org/10.1016/S1464-1909(00)00090-3.

Boger, D. V. (2013). Rheology of slurries and environmental impacts in the mining industry. Annual Review of Chemical and Biomolecular Engineering, 4(1), 239-257. PMid:23540291. http:// dx.doi.org/10.1146/annurev-chembioeng-061312-103347.

Briggs, R. J. (1964). Electron-stream interaction with plasmas. Cambridge: MIT Press. http://dx.doi.org/10.7551/mitpress/2675.001.0001.

Brock, R. R. (1969). Development of roll wave trains in open channels. Journal of the Hydraulics Division, 95(4), 1401-1427. http:/ / dx.doi.org/10.1061/JYCEAJ.0002132.

Brook, B. S., \& Pedley, T. J. (2002). A model for time-dependent flow in (giraffe jugular) veins: uniform tube properties. Journal of Biomechanics, 35(1), 95-107. PMid:11747888. http://dx.doi. org/10.1016/S0021-9290(01)00159-2.

Buzzo, B. (2019, 31 de janeiro). Tijolo de rejeito é opção segura para evitar rompimento de barrage. Retrieved in 2020, October 27, from https://www.ecycle.com.br/7035-tijolo-rejeito-rompimentode-barragem

Campomaggiore, F., Di Cristo, C., Iervolino, M., \& Vacca, A. (2016). Inlet effects on roll wave development in shallow turbulent open-channel flows. Journal of Hydrology and Hydromechanics, 64(1), 45-55. http://dx.doi.org/10.1515/johh-2016-0003.

Cao, Z., Hu, P., Hu, K., Pender, G., \& Liu, Q. (2015). Modelling roll waves with shallow water equations and turbulent closure. Journal of Hydraulic Research, 53(2), 161-177. http://dx.doi.org/1 $0.1080 / 00221686.2014 .950350$.

Chambon, G., Ghemmour, A., \& Naaim, M. (2014). Experimental investigation of viscoplastic free-surface flows in a steady uniform regime. Journal of Fluid Mechanics, 754, 332-364. http://dx.doi. org/10.1017/jfm.2014.378.

Cornish, V. (1910). Waves of the sea and other waves. London: Adelphi Terrace.

Coussot, P. (1994). Steady, laminar, flow of concentrated mud suspensions in open channel. Journal of Hydraulic Research, 32(4), 535-559. http://dx.doi.org/10.1080/00221686.1994.9728354. 
Coussot, P. (2014). Yield stress fluid flows: a review of experimental data. Journal of Non-Newtonian Fluid Mechanics, 211, 31-49. http:/ / dx.doi.org/10.1016/j.jnnfm.2014.05.006.

Cunha, E. F. (2017). Implementação de um aparato experimental para medição de instabilidade em superfície livre com fluido não-Newtoniano (Tese de doutorado). Faculdade de Engenharia de Ilha Solteira, Universidade Estadual Paulista Júlio de Mesquita Filho, Ilha Solteira.

Di Cristo, C., \& Vacca, A. (2005). On the convective nature of roll waves instability. Journal of Applied Mathematics, 3(3), 259-271. http://dx.doi.org/10.1155/JAM.2005.259.

Di Cristo, C., Iervolino, M., \& Vacca, A. (2013a). On the applicability of minimum channel length criterion for roll waves in mud-flows. Journal of Hydrology and Hydromechanics, 61(4), 286-292. http:// dx.doi.org/10.2478/johh-2013-0036.

Di Cristo, C., Iervolino, M., \& Vacca, A. (2013b). Waves dynamics in a linearized mud-flow shallow model. Applied Mathematical Sciences, 7(8), 377-393. http://dx.doi.org/10.12988/ ams.2013.13033.

Dressler, R. F. (1949). Mathematical solution of the problem of roll waves in inclined open channels. Communications on Pure and Applied Mathematics, 2(2-3), 149-194. http://dx.doi.org/10.1002/ cpa.3160020203.

Fei, J., Jie, Y., Xiong, H., \& Wu, Z. (2021). Granular roll waves along a long chute: from formation to collapse. Powder Technology, 377, 553-564. http://dx.doi.org/10.1016/j.powtec.2020.09.007.

Ferreira, F. O. (2013). Estabilidade e controle dinâmico de roll waves (Tese de doutorado). Faculdade de Engenharia de Ilha Solteira, Universidade Estadual Paulista Júlio de Mesquita Filho, Ilha Solteira.

Ferreira, F. O., Maciel, G. F., Fiorot, G. H., \& Cunha, E. F. (2014). Numerical analysis of roll waves generation on non-Newtonian fluids flowing down an inclined plane. Advanced Materials Research, 1006, 160-167. http://dx.doi.org/10.4028/www.scientific.net/ AMR.1006-1007.160.

Ferreira, R. B., Falcão, D. S., Oliveira, V. B., \& Pinto, A. M. F. R. (2015). Numerical simulations of two-phase flow in proton exchange membrane fuel cells using the volume of fluid method - A review. Journal of Power Sources, 277, 329-342. http://dx.doi. org/10.1016/j.jpowsour.2014.11.124.

Fiorot, G. H., Ferreira, F. O., Dupont, P., \& Maciel, G. F. (2018). Roll Waves mathematical model as a risk-Assessment tool: case study of Acquabona catchment. Journal of Hydraulic Engineering, 144(12), 05018009. https://doi.org/10.1061/(ASCE)HY.19437900.0001538 .

Fiorot, G. H., Maciel, G. F., Cunha, E. F., \& Kitano, C. (2015). Experimental setup for measuring roll waves on laminar open channel flows. Flow Measurement and Instrumentation, 41, 149-157. http://dx.doi.org/10.1016/j.flowmeasinst.2014.10.020.
Forterre, Y., \& Pouliquen, O. (2003). Long - surface - wave instability in dense granular flows. Journal of Non-Newtonian Fluid Mechanics, 486, 21-50. http://dx.doi.org/10.1017/S0022112003004555.

Fraccarollo, L., \& Papa, M. (2000). Numerical simulation of real debris flow events. Physics and Chemistry of the Earth. Part B: Hydrology, Oceans and Atmosphere, 25(9), 757-763. http://dx.doi. org/10.1016/S1464-1909(00)00098-8.

Freydier, P., Chambon, G., \& Naaim, M. (2017). Experimental characterization of velocity fields within the front of viscoplastic surges down an incline. Journal of Non-Newtonian Fluid Mechanics, 240, 56-69. http://dx.doi.org/10.1016/j.jnnfm.2017.01.002.

Gao, D., Morley, N. B., \& Dhir, V. (2003). Numerical simulation of wavy falling film flow using VOF method. Journal of Computational Physics, 192(2), 624-642. http://dx.doi.org/10.1016/j. jcp.2003.07.013.

Gaster, M. (1962). A note on the relation between temporallyincreasing and spatially-increasing disturbances in hydrodynamic stability. Journal of Fluid Mechanics, 14(2), 222-224. http://dx.doi. org/10.1017/S0022112062001184.

Gray, J. M. N. T., \& Edwards, A. N. (2014). A depth-averaged $\mu(\mathrm{I})$-rheology for shallow granular free-surface flows. Journal of Fluid Mechanics, 755, 503-534. http://dx.doi.org/10.1017/ jfm.2014.450.

He, M., Zhang, K., Wang, J. (2020). Influence factors of hydraulic parameters of roll waves in overland flow. Advances in Water Science, 31(1), 102-111. http://dx.doi.org/ 10.14042/j. cnki.32.1309.2020.01.011.

Hirt, C. W., \& Nichols, B. D. (1981). Volume of fluid (VOF) method for the dynamics of free boundaries. Journal of Computational Physics, 39(1), 201-225. http://dx.doi.org/10.1016/00219991(81)90145-5.

Holmås, H. (2010). Numerical simulation of transient roll-waves in two-phase pipe flow. Chemical Engineering Science, 65(5), 18111825. http://dx.doi.org/10.1016/j.ces.2009.11.031.

Hwang, S. H., \& Chang, H. C. (1987). Turbulent and inertial roll waves in inclined film flow. Physics of Fluids, 30(5), 1259-1268. http://dx.doi.org/10.1063/1.866292.

Institut National de Recherche en Sciences et Technologies pour L'environnement et L'agriculture - IRSTEA. (2001). Connaitre les laves torrentielles. Grenoble: IRSTEA. Retrieved in 2020, October 27, from http://www.irstea.fr/lespace-jeunesse/nosressources/ videos-0

Issakhov, A., \& Zhandaulet, Y. (2020). Numerical study of dam break waves on movable beds for complex terrain by volume of fluid method. Water Resources Management, 34(2), 463-480. http:/ / dx.doi.org/10.1007/s11269-019-02426-1. 
Ivanova, K. A., Gavrilyuk, S. L., Nkonga, B., \& Richard, G. L. (2017). Formation and coarsening of roll waves in shear shallow water flows down na inclined rectangular channel. Computers \& Fluids, 159, 189-203. http://dx.doi.org/10.1016/j.compfluid.2017.10.004.

Jeffreys, H. (1925). The flow of water in an inclined channel of rectangular section. Philosophical Magazine, 49(293), 793-807. http:/ / dx.doi.org/10.1080/14786442508634662.

Kajiuchi, T., \& Saito, A. (1984). Flow enhancement of laminar pulsating flow of Bingham plastic fluids. Journal of Chemical Engineering of Japan, 17(1), 34-38. http://dx.doi.org/10.1252/ jcej.17.34.

Kan, Z. H. U., Boudlal, A., \& Mompean, G. (2018). Nonlinear stability of roll waves down an inclined falling film. World Journal of Research and Review, 6, 5.

Kuehne, R. (1984). Macroscopic freeway model for dense trafficstop-start waves and incident detection. In Proceedings of the Ninth International Symposium on Transportation and Traffic Theory (Vol. 9, pp. 21-42). London: CRC Press.

Liu, J., \& Gollub, J. P. (1994). Solitary wave dynamics of film flows. Physics of Fluids, 6(5), 1702-1712. http://dx.doi. org/10.1063/1.868232.

Liu, J., \& Mei, C. C. (1994). Roll waves on a layer of a muddy fluid flowing down a gentle slope - a bingham model. Physics of Fluids, 6(8), 2577-2590. http://dx.doi.org/10.1063/1.868148.

Long, W. J., Khayat, K. H., Yahia, A., \& Xing, F. (2017). Rheological approach in proportioning and evaluating prestressed selfconsolidating concrete. Cement and Concrete Composites, 82, 105-116. http://dx.doi.org/10.1016/j.cemconcomp.2017.05.008.

Maciel, G. F. (2002). Roll waves evolution in high gradient channels to a non-newtonian rheology. In B. H. V. Topping \& Z. Bittnar (Eds.), Proceedings of the Third International Conference on Engineering Computational Technology. Stirlingshire, UK: Civil-Comp Press. http://dx.doi.org/10.4203/ccp.76.37.

Maciel, G. F., \& Lledo, F. (1999). Analogia de roll waves ao problema van der pol. Revista Brasileira de Recursos Hídricos, 4(4), 17-23.

Maciel, G. F., de Oliveira Ferreira, F., \& Fiorot, G. H. (2013). Control of instabilities in non-Newtonian free surface fluid flows. Journal of the Brazilian Society of Mechanical Sciences and Engineering, 35(3), 217-229. http://dx.doi.org/10.1007/s40430013-0025-y.

Maciel, G. F., Toniati, A. L., \& Ferreira, F. O. (2018). Modelo matemático simplificado para determinar a capacidade erosiva de um escoamento lamoso em regime laminar pulsante. Engenharia Sanitaria e Ambiental, 23(5), 913-922. http://dx.doi.org/10.1590/ s1413-41522018175446.
Maciel, G. Ferreira, F \& Fiorot, G. (2017). Experimental apparatus for roll wave measurements and comparison with a $1 \mathrm{D}$ mathematical model. Journal of Hydraulic Engineering, 143(11), 04017046. http:/ / dx.doi.org/10.1061/(ASCE)HY.1943-7900.0001366.

Malet, J. P., Remaître, A., Maquaire, O., Ancey, C., \& Locat, J. (2003). Flow susceptibility of heterogeneous marly formations: implications for torrent hazard control in the Barcelonnette basin (Alpes-de-Haute-Provence, France). In D. Rickenmann and C. L. Chen (Eds.), Proceedings of the 3rd Int. Conf. on DebrisFlow Hazards Mitigation (pp. 351-362). Rotterdam, Netherlands: Millpress.

Malkin, A. Y., \& Isayev, A. I. (2012). Rheology: concepts, methods and applications. Toronto: ChemTec Publishing.

Mcardell, B. W. (2016). Field measurements of forces in debris flows at the Illgraben: implications for channel-bed erosion. International Journal of Erosion Control Engineering, 9(4), 194-198. http://dx.doi.org/10.13101/ijece.9.194.

Miao, Y., Jiaguo, G., Yong, Z, Wang, H., He, X., \& Zhao, C. (2020). Evolution rules of rolling waves on slopes based on artificial flat slopes of loess. Journal of Hydrologic Engineering, 25(5), 04020014. https://doi.org/10.1061/(ASCE)HE.19435584.0001899 .

Needham, D. J., \& Merkin, J. H. (1987). An infinite period bifurcation arising in roll waves down open inclined channel. Proceedings - Royal Society. Mathematical and Physical Sciences, 405, 103-116. http://dx.doi. org/10.1098/rspa.1986.0043.

$\mathrm{Ng}$, C. O., \& Mei, C. C. (1994). Roll waves on a layer of fluid mud modelled as a power law fluid. Journal of Fluid Mechanics, 263, 151184. http://dx.doi.org/10.1017/S0022112094004064.

Piau, J. M. (2007). Carbopol gels: elastoviscoplastic and slippery glasses made of individual swollen sponges: Meso-and macroscopic properties, constitutive equations and scaling laws. Journal of NonNewtonian Fluid Mechanics, 144(1), 1-29. http://dx.doi.org/10.1016/j. jnnfm.2007.02.011.

Ponce, V. M. (2005, 24 de fevereiro). Project Photos MM: Turner Reservoir, San Diego Country, California. Retrieved in 2020, October 27, from http://ponce.sdsu.edu/projectphotosmm.html

Ponce, V. M., \& Guzmán, B. C. (2019, 13 de junho). The control of roll waves in channelized rivers. Retrieved in 2020, October 27, from http://ponce.sdsu.edu/the_control_of_roll_waves.html

Razis, D., Kanellopoulos, G., \& van der Weele, K. (2019). A dynamical systems view of granular flow: from monoclinal flood waves to roll waves. Journal of Fluid Mechanics, 869, 143-181. http:/ / dx.doi.org/10.1017/jfm.2019.168.

Tamburrino, A., \& Ihle, C. F. (2013). Roll wave appearance in bentonite suspensions flowing down inclined planes. Journal of 
Hydraulic Research, 51(3), 330-335. http://dx.doi.org/10.1080/0 0221686.2013 .769468$.

Zanuttigh, B., \& Lamberti, A. (2002). Roll waves simulation using shallow water equations and weighted average flux method. Journal of Hydraulic Research, 40(5), 610-622. http://dx.doi. org/10.1080/00221680209499905.

Zanuttigh, B., \& Lamberti, A. (2007). Instability and surge development in debris flows. Reviews of Geophysics, 45(3), 1-45. http://dx.doi.org/10.1029/2005RG000175.

Zhao, C., Gao, J., Zhang, M., Zhang, T., \& Wang, F. (2015). Response of roll wave to suspended load and hydraulics of overland flow on steep slope. Catena, 133, 394-402. http://dx.doi.org/10.1016/j. catena.2015.06.010.

\section{Authors contributions}

Fabiana de Oliveira Ferreira: First author who contributed to literature review, Performed the simulation tests and discussion of results, as well as writing and formatting of the article.

Geraldo de Freitas Maciel: Research coordinator, paper conception, analysis and completion of results and discussion.

João Batista Pereira: Literature review, writing, revision and formatting of the article.

Editor Chefe: Adilson Pinheiro

Editor Associado: Iran Eduardo Lima Neto 


\section{APPENDIX A}

In the spatial stability analysis, the dispersion equation obtained with the introduction of the disturbance is given by equation A1.

$\left(\alpha-\frac{1}{F r^{2}}\right) k^{2}+\left[-\frac{(n+1)(2 n+1)}{(n+1+n C)} i-2 \alpha \omega\right] k+\omega^{2}+n(1-C) i \omega=0$

Considering: $k=k_{r}+i k_{i}$ and $\omega_{i}=0$, then, $\omega=\omega_{r}$. Thus, $k\left(\omega_{r}\right)$ is given by equation A2.

$k\left(\omega_{r}\right)=\frac{1}{\left(\alpha-\frac{1}{F r^{2}}\right)}[(2 \alpha \omega+\varphi i) \pm \sqrt{c+d i}]$

where:

$c=4 \omega^{2}\left(\alpha^{2}-\alpha+\frac{1}{F r^{2}}\right)-\varphi^{2}$

$d=4 \omega\left(\alpha \varphi-\alpha \vartheta+\frac{\vartheta}{F r^{2}}\right)$

The spatial amplification rate is given by equation A5 and the number of waves is described by equation A6.

$k_{i}\left(\omega_{r}\right)=\left[\frac{1}{2\left(\alpha-\frac{1}{F r^{2}}\right)}\right]\left[\varphi \pm \sqrt{\frac{1}{2}\left(\sqrt{c^{2}+d^{2}}-c\right)}\right]$
$k_{r}\left(\omega_{r}\right)=\left[\frac{1}{2\left(\alpha-\frac{1}{F r^{2}}\right)}\right]\left[2 \alpha \omega \pm \sqrt{\frac{1}{2}\left(\sqrt{c^{2}+d^{2}}+c\right)}\right]$

The functions $k_{i}\left(\omega_{r}\right)$ and $k_{r}\left(\omega_{r}\right)$ (equations A5 and A6) have singularities when: $F r=\frac{1}{\sqrt{\alpha}}=F r_{s}$. However, when $F r>0, F r \neq F r_{s}$ and $k_{i}\left(\omega_{r}\right)=0$, we obtain equation A7.

$\left[\varphi \pm \sqrt{\frac{1}{2}\left(\sqrt{c^{2}+d^{2}}-c\right)}\right]=0$

By solving equation A7, we obtain a zero spatial amplification rate, if $F r=F r_{\text {mim }}$, as established by Maciel et al. (2013). Numerically, it can be observed that $F r>F r_{\text {mim }}$, when $k_{i}\left(\omega_{r}\right)^{-}<0$, which means that the spatial growth rate propagates in the positive direction $(G a s t e r$, 1962), as shown in Figure A1.
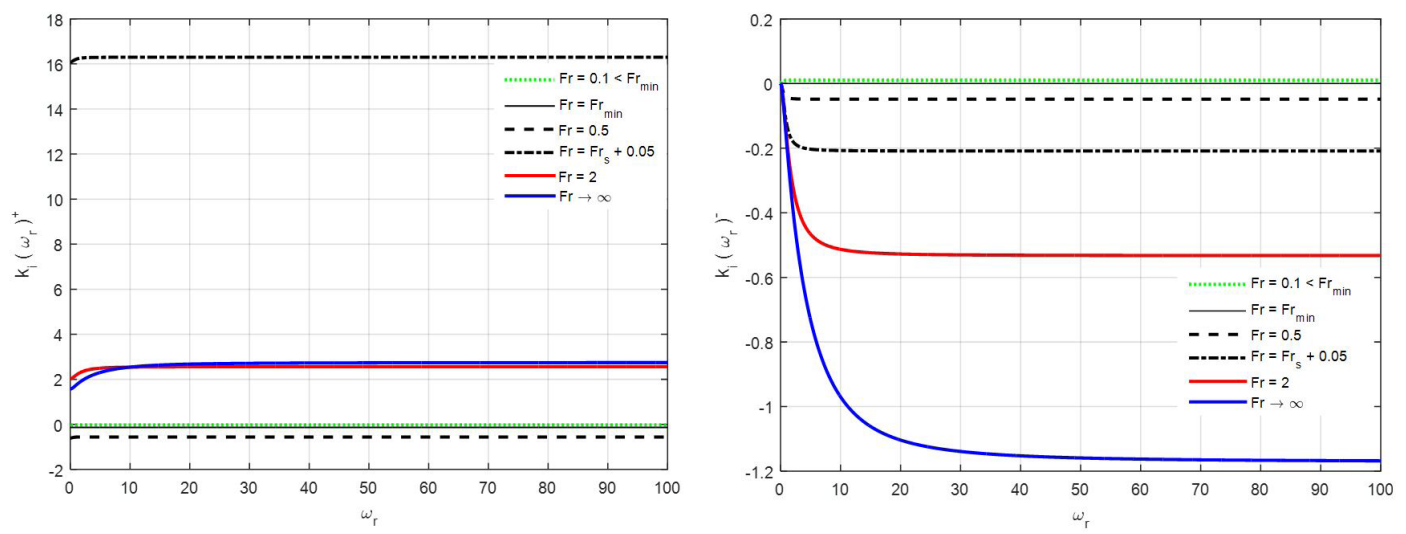

Figure A1. Behavior of the function $\mathbf{k}_{\mathbf{i}}\left(\boldsymbol{\omega}_{\mathbf{r}}\right)^{+}$(positive branch) and $\mathbf{k}_{\mathbf{i}}\left(\boldsymbol{\omega}_{\mathbf{r}}\right)^{-}$(negative branch), with $\boldsymbol{n}=0.4, \boldsymbol{C}=0.1$ and varying Froude numbers. 
It is possible to observe that the spatial growth rate is asymptotic (Figure A1), being the asymptote given by equation A8. Additionally, it is important to notice that, for high Froude numbers $(F r \rightarrow \infty)$, the asymptote depends on the rheological properties of the fluid $(n, C)$.

$$
\lim _{\omega_{r} \rightarrow \infty} k_{i}\left(\omega_{r}\right)=\frac{1}{2\left(\alpha-\frac{1}{F r^{2}}\right)}\left[-\varphi \pm \frac{\left(\alpha \vartheta-\alpha \varphi-\vartheta F r^{-2}\right)}{\left(\alpha^{2}-\alpha+F r^{-1}\right)^{I / 2}}\right]
$$

Figure A2 shows the behavior of the function $k_{r}\left(\omega_{r}\right)$, with $n=0.4, C=0.1$ and varying Froude numbers.

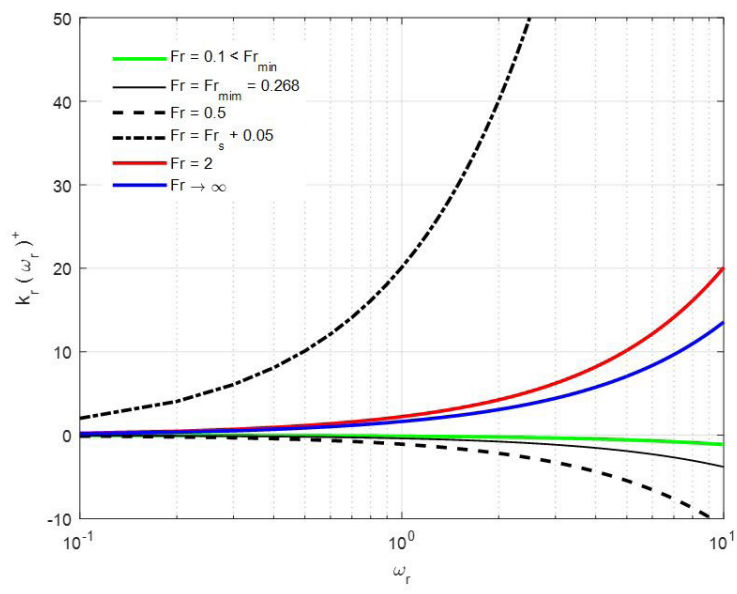

a) Positive branch

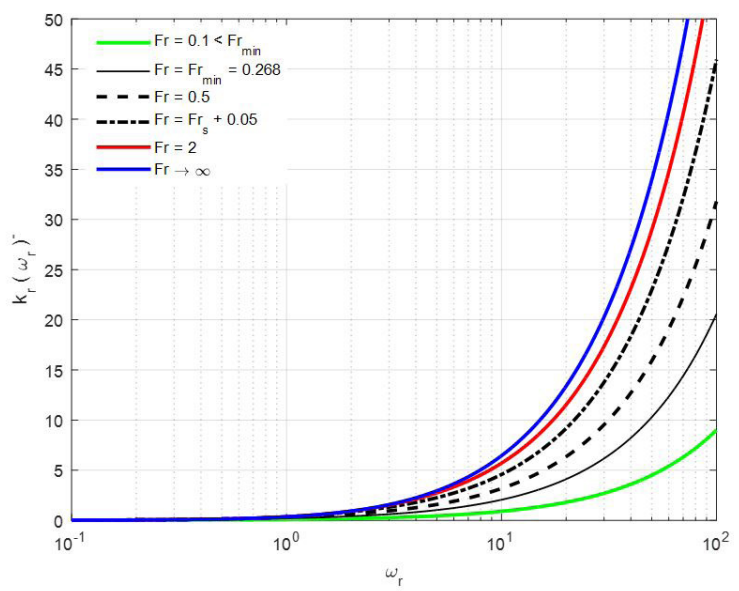

b) Negative branch

Figure A2. Behavior of the function $\mathbf{k}_{\mathbf{r}}\left(\boldsymbol{\omega}_{\mathbf{r}}\right)^{+}$(positive branch) and $\mathbf{k}_{\mathbf{r}}\left(\boldsymbol{\omega}_{\mathbf{r}}\right)^{-}$(negative branch), with $\boldsymbol{n}=0.4, \boldsymbol{C}=0.1$ and varying Froude numbers.

Through the analysis of Figure A2.a, it can be seen that the appropriate Froude numbers for wave generation are found in the domain $\left\{k_{r}\left(\omega_{r}\right)^{+} \in \mathbb{R} / k_{r}\left(\omega_{r}\right)^{+}<0\right.$ and $\left.k_{r}\left(\omega_{r}\right)^{+}>0\right\}$.

In Figure A2.b, $F r>F r_{\min }$ is in the domain of $k_{r}\left(\omega_{r}\right)^{-}>0$. Therefore, $k_{r}\left(\omega_{r}\right)=0$ becomes a critical condition, represented by equation A8. The next step is to identify the critical frequency $\left(\omega_{c}\right)$, when $k_{r}\left(\omega_{c}\right)=0$.

$\left[\frac{1}{2\left(\alpha-\frac{1}{F r^{2}}\right)}\right]\left[2 \alpha \omega \pm \sqrt{\frac{1}{2}\left(\sqrt{c^{2}+d^{2}}+c\right)}\right]=0$

By solving equation A9, for $F r>0$ and $F r \neq F r_{s}$, the critical disturbance frequency is given by equation A10:

$\omega=\omega_{c}=\frac{1}{2 \alpha} \sqrt{\left(\alpha-\frac{1}{F r^{2}}\right) \vartheta^{2}-2 \alpha \vartheta \varphi}$

It is important to notice that $\omega_{c}$ is a pure imaginary number when $2 \alpha \vartheta \varphi>\left(\alpha-1 / F^{2}\right) \vartheta^{2}$. Equation 10 assumes a real value when $n=0$ and/or $C=1$ (in both cases, there is no disturbance amplification). Thus, the cut-off frequency of the disturbance is rewritten in the complex form (equation A11):

$\omega_{c}=\left|\omega_{c}\right| e^{i \angle \omega_{c}}$

Lastly, a condition for the amplification of roll waves in the positive direction $\omega<\left|\omega_{c}\right|$ is determined by the algebraic resolution of $k_{r}\left(\omega_{r}\right)^{-}>0$.

After determining the expression for the critical disturbance frequency $\left(\left|\omega_{c}\right|\right)$, it is necessary to investigate its behavior towards the rheological properties of the fluid. Through equation A10, it is possible to notice that, for flows with low Froude numbers, the cutoff frequency $\left(\omega_{c}\right)$ depends on the Froude number and on the rheology of the fluid. For high Froude numbers $(F r \rightarrow \infty)$, though, the cut-off frequency exclusively depends on the rheology of the fluid.

Figure A3 exhibits the influence exerted by the rheological parameters $(n, C)$ on the cut-off frequency, when $F r>F r_{\text {min }}$. 


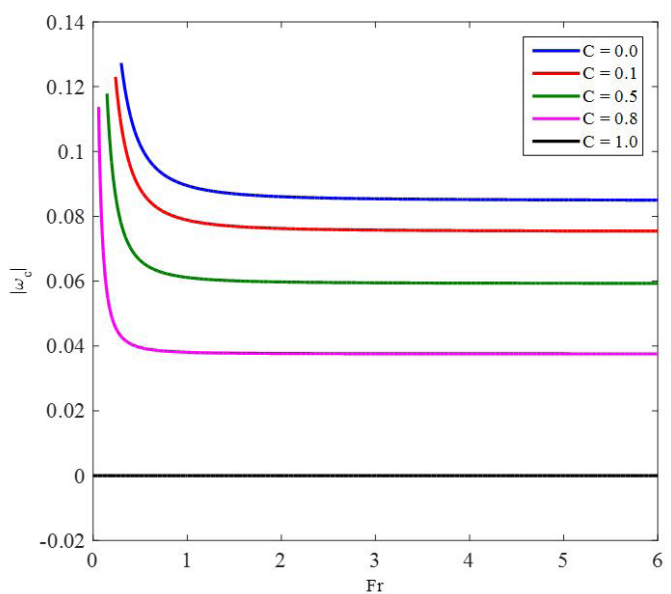

(a) Cut-off frequency for $n=0.4$

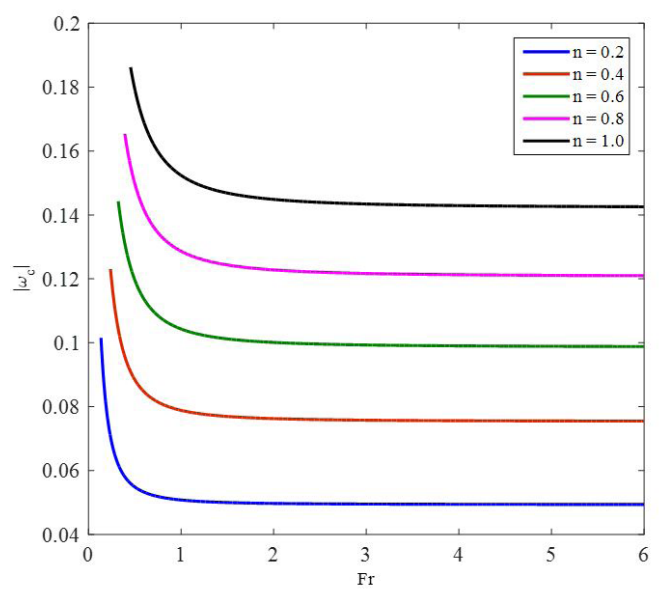

(b) Cut-off frequency for $C=0.1$

Figure A3. Influence exerted by the rheological parameters $\boldsymbol{n}, \boldsymbol{C}$ on the cut-off frequency, when $\boldsymbol{F r}>\boldsymbol{F} \boldsymbol{r}_{\boldsymbol{m i n}}$ : (a) Influence of parameter $\boldsymbol{C}$, (b) Influence of the flow index of the fluid $\boldsymbol{n}$.

Through the analysis of Figure A3.a, it is possible to observe that an increase of parameter $C$ (i.e. an increase of the yield stress of the fluid over the shear stress applied on the bottom) results in a decrease of the domain of appropriate disturbance frequencies for roll wave generation. Furthermore, a decrease in the flow index of the fluid also causes a reduction of such domain (Figura A3.b). This means that, under same flow conditions, roll waves propagate at lower frequencies in non-Newtonian fluids than they do in Newtonian fluids. 